\title{
Production of a Functional Catalytic Antibody ScFv-NusA Fusion Protein in Bacterial Cytoplasm
}

\author{
Lei Zheng, Ulrich Baumann and Jean-Louis Reymond* \\ Department of Chemistry and Biochemistry, University of Bern, Freiestrasse 3, CH-3012 Bern, Switzerland
}

Received November 4, 2002; accepted February 10, 2003

Functional expression of catalytic antibodies in the cytoplasm of E. coli is potentially of great interest in searching for new catalysts by genetic selection. Herein, a catalytic antibody single chain Fv (ScFv) 14D9, which catalyzes a highly enantioselective protonation, was expressed as a NusA fusion protein under the T7 promoter. A functional disulfide-containing ScFv fusion protein was obtained in the oxidizing environment of bacterial cytoplasm. The 14D9 ScFv could not be overexpressed alone without NusA fusion. The highly soluble NusA protein most likely retards aggregate formation of ScFv and indirectly supports correct folding and disulfide bridge formation in the fusion construct ScFv-NusA. The ScFv-NusA fusion product shows highly enantioselective, specific, hapten inhibited catalytic activity comparable to its parent monoclonal antibody, 14D9. The NusA fusion method might be generally helpful for functional antibody expression in vivo and for the new development of biocatalysts by genetic selection.

Key words: catalytic antibody; cytoplasmic expression; enantioselectivity; single chain Fv; NusA.

Abbreviations: ScFv, Single chain variable fragment; NusA, N utilization substance protein A.

Recombinant antibody fragments are the workhorses of antibody research since they offer a convenient format for mutational manipulation of their sequences and functional specificities (1). Although all antibodies have a common framework and thus possess very similar structures, their expression in recombinant format is not uniform and must be optimized on a case by case basis, some of which yield very respectable expression levels (2). Available expression formats include the periplasmic expression of Fab-fragments (3), which may be humanized (2), the single-chain Fv format ( $\mathrm{ScFv}$ ) (4), and the helix-stabilized format (5). In relation to our interest in the development of catalytic antibodies (6-7), we have been particularly interested in finding a general format for the cytoplasmic expression of functional antibody fragments (8). Indeed such a format would make it possible to establish genetic selection schemes for the optimization of catalytic function by working on the catalysis of reactions essential to cell survival, such as the liberation of an essential growth factor from an inactive precursor, or the catalysis of a metabolically essential reaction within an auxotrophic host $(9,10)$.

Herein we report a novel method for the production of a functional $\mathrm{ScFv}$ fragment in the oxidizing bacterial cytoplasm. The system is demonstrated by the catalytic antibody 14D9, a catalytic antibody against piperidinium hapten 1a (11), which catalyzes the highly enantioselective protonation of enol ethers such as $\mathbf{2}$ to give optically pure carbonyl products such as $(S)$-ketone 3 (12), with absolute control of enantioselectivity (14). The kinetic

"To whom correspondence should be addressed. Tel: +41-31-631-4325, Fax: +41-31-631-8057, E-mail: jean-louis.reymond@ioc.unibe.ch constants for the reaction $\left(k_{\text {cat }} / k_{\text {uncat }}=10^{4}, k_{\text {cat }}=0.4 \mathrm{~s}^{-1}\right.$ at pH6.0) make it one of the fastest and most practical catalytic antibodies reported to date (15). The ScFv-fragment is fused with the NusA protein ( $\mathrm{N}$ utilization substance protein A), which shows the highest solubility in $E$. coli (16). A stain bearing a defect in the reductase for thioredoxin and glutathione, which has been shown to accumulate active oxidizing enzymes in the cytoplasm (17), provides a potentially favorable environment for disulfide bond formation of single chain $\mathrm{Fv}$. We show that the combination of NusA fusion and an oxidizing cytoplasmic environment facilitates the expression of a functional catalytic antibody fragment.

\section{MATERIALS AND METHODS}

Construction of Single Chain Fv 14D9-The Fd and kappa chain gene fragments of 14D9 were amplified by PCR as described (18). Amplified PCR products were digested with XhoI-SpeI for the Fd gene fragment and SacI-XbaI for the kappa chain gene fragment, and ligated into phage display vector pcomb3H (19) to give pcomb3H14D9. All PCRs were carried out with Vent proof-reading polymerase (New England Biolabs) to ensure the highest fidelity. The VL and VH domains were PCR amplified with primer pairs, VL_Bn 5'-GCGGCCAGCGAGCTCGTGACACAGTC-3' and Linker_rev 5'-GAACCTTCAGAGCTTTTGCCGCTACCGGAAGTGCTGCCTTTGATCTCAAGCTTTGTGCC-3' for the VL fragment, Linker_for 5'GCGGCAAAAGCTCTGAAGGTTCTGGCAGCACCAAAGGTCAGGTTCAGCTGCTGCTCGAGCAG-3' and VH_end2 CGTAGTCGACTCAGG-AGAGACGGTGACCGT (the SalI site is underlined) for the VH fragment. Single chain Fv was assembled following a standard protocol (4). 
Cloning of ScFv $14 D 9$ into pET43.1a-The plasmid pET43.1a (Novagen, Bad Soden, Germany) was digested with SmaI-XhoI. The large fragment was purified from an agrose gel and dephosphorylated by shrimp alkaline phosphatase to minimize the ligation background. After treatment with SalI, the amplified $\mathrm{ScFv}$ gene fragment was inserted into pET43.1a by half-blunt end ligation to give pET-14D9nus. A new PCR amplification was done with VL53 5'-GCAGTGACATATGGAGCTCGTGATGACACAGTCTCC-3' (the NdeI site is underlined) instead of VL_Bn. The plasmid pET43.1a was digested with NdeIXhoI, the large fragment purified from an agrose gel was ligated with an amplified $\mathrm{ScFv}$ fragment treated with NdeI-SalI to give plasmid pET-14D9. Both clones were confirmed by DNA sequencing.

Cytoplasmic Expression and Purification-BL21(DE3) $\mathrm{TrxB}^{-}$, Gor $^{-}$, under the name of Origami ${ }^{\mathrm{TM}}$, and strain BL21(DE3), are available from Novagen. The procedures for growth of the bacteria and induction of single chain Fv were conducted according to a standard protocol. Briefly, an overnight preculture grown in LB medium supplemented with responding antibiotics $[50 \mu \mathrm{g} / \mathrm{ml}$ Carbenicillin, $35 \mu \mathrm{g} / \mathrm{ml}$ Kanamycin, and $15 \mu \mathrm{g} / \mathrm{ml}$ Tetracycline for BL21(DE3) TrxB-,Gor- ; $50 \mu \mathrm{g} / \mathrm{ml}$ Carbenicillin for BL21(DE3)] was incubated in 1 liter of the same medium at 1:500 dilution and grown until mid exponential stage $\left(A_{600}=0.5\right)$ at $22^{\circ} \mathrm{C}$. Induction was started by adding isopropyl thio- $\beta$-D-galactoside (IPTG) to the culture at a final concentration of $1 \mathrm{mM}$, and growth was continued for $15 \mathrm{~h}$ at $22^{\circ} \mathrm{C}$. The cells were pelleted, resuspended in lysis buffer (Tris $20 \mathrm{mM}$ pH 8.0, $300 \mathrm{mM} \mathrm{NaCl}$, $10 \mathrm{mM}$ imidazole), and the cytoplasmic proteins were extracted from the cells by sonication and subsequent centrifugation. The supernatant was loaded onto a $\mathrm{Ni}^{2+}$ NTA (IMAC) column (Qiagen), and the column was washed extensively with washing buffer $(20 \mathrm{mM}$ Tris/ $\mathrm{HCl}, 300 \mathrm{mM} \mathrm{NaCl}, 40 \mathrm{mM}$ imidazole $\mathrm{pH}$ 8.0). The fusion $\mathrm{ScFv}$ was eluted with elution buffer $(20 \mathrm{mM}$ Tris/ $\mathrm{HCl}$, $300 \mathrm{mM} \mathrm{NaCl}, 250 \mathrm{mM}$ imidazole $\mathrm{pH}$ 8.0).

$S c F v$ Preparation from the Fusion Protein-The fusion protein in PBS buffer (pH7.4) was digested with Thrombin protease (Roche) for $12 \mathrm{~h}$ at $22^{\circ} \mathrm{C}$. The ratio of fusion protein to protease was optimized and set to 0.5 unit/mg protein, and the protease-treated solution was loaded directly onto the $\mathrm{Ni}^{2+}$-NTA column. The passthrough was fed onto a hapten affinity column, in which the hapten was coupled covalently to DEAE-Sepharose (Pharmacia) (20). The column was washed with the same buffer and the $\mathrm{ScFv}$ was eluted with $0.2 \mathrm{mM}$ Glycine/ $\mathrm{HCl}, \mathrm{pH} 3.0$, and immediately neutralized with 1M Tris/ $\mathrm{HCl}, \mathrm{pH}$ 9.0. The eluate was dialyzed against PBS buffer (pH7.4) overnight at $4^{\circ} \mathrm{C}$ and concentrated with CentriprepTM YM-10 and YM-30 (Amicon, Millipore).

The integrity of the recombinant fusion $\mathrm{ScFv}$ and its purification were checked by SDS/PAGE on a homogeneous $15 \%$ gel with Coomassie Brilliant Blue staining. The final protein concentrations were measured by UV spectrophotometry with extinction coefficient $A_{280}=1.35$ $\mathrm{cm}^{2} \cdot \mathrm{mg}^{-1}$.

Catalytic Activity Assay-Catalytic reactions were carried out by mixing $0.6 \mu \mathrm{l}$ of a $10 \mathrm{mM}$ stock solution of substrate 2 in acetonitrile/water 1:1 (Fig. 1) with $19.2 \mu \mathrm{l}$ protein solutions at a concentration of $1 \mathrm{mg} / \mathrm{ml}$ in PBS

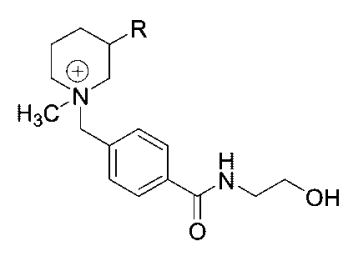

1a $\left(\mathrm{R}=\mathrm{CH}_{2} \mathrm{NHCO}\right.$-carrier protein)

$1 b(R=H)$

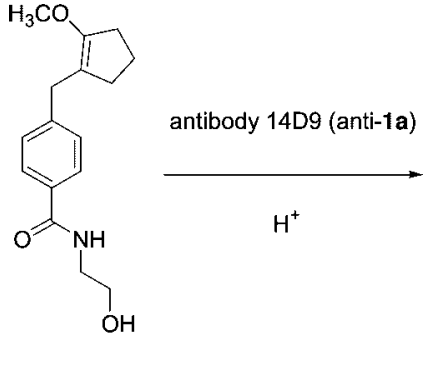

2

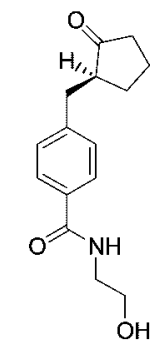

(S)-3
Fig. 1. Enantioselective protonation catalyzed by antibody $14 D 9$.

(pH7.4) at $22^{\circ} \mathrm{C}$ (final concentration of 2: $300 \mu \mathrm{M}$ ). An identically prepared solution containing $0.2 \mu \mathrm{l}$ of $5 \mathrm{mM}$ inhibitor 1b (final concentration: $50 \mu \mathrm{M}$ ) was used to check specific inhibition. All reactions were monitored by HPLC. The substrate and product were separated on an analytical RP-C18 column (218TP54, $22 \mathrm{~cm} \times 0.45 \mathrm{~cm}$, $300 \AA$ poresize, Vydac, USA). Retention times were as follows (eluent: $1.5 \mathrm{~mL} \cdot \mathrm{min}^{-1} \mathrm{H}_{2} \mathrm{O} /$ acetonitrile $=75: 25$, detection by UV at $230 \mathrm{~nm}): t_{\mathrm{R}}(2)=3.3 \mathrm{~min}, t_{\mathrm{R}}(3)=15.7$ $\mathrm{min}$. The percentage conversion as indicated in Fig. 3 was calculated from peak integration.

Enantioselectivity Assay-Substrate 2 was incubated with the antibody samples as above on a $200 \mu \mathrm{l}$ scale. The entire reaction mixture was injected onto RP-C18-HPLC and the product ketone 3 peak was collected and lyophilized. The residue was taken up in hexane/isopropanol = $1: 1$, and analyzed on a chiral-phase column (Chiralpak OD, Daicel, $22 \mathrm{~cm} \times 0.45 \mathrm{~cm}$ ), which allows the separation of the two enantiomeric products (eluent: hexane/isopropanol $=7: 3 ; 1 \mathrm{ml} / \mathrm{min})$ as $t_{\mathrm{R}}\left[(R)-3=8.6 \mathrm{~min}, t_{\mathrm{R}}(S)-3\right]=12.4$ min. The absolute configuration of the products was established earlier by chemical correlation (21).

\section{RESULTS}

The antibody 14D9 Fab domain was cloned from the 14D9 hybridoma cell line (Details of the hapten-affinity column preparation and use will be described elsewhere). To assemble the two variable domains, we used a known modified 18-amino acid linker derived from the classical Gly-Ser linker, including three charged residues (Lys, Lys, Glu) to enhance the solubility of the ScFv construct (Details of the hapten-affinity column preparation and use will be described elsewhere). The assembled $\mathrm{ScFv}$ was cloned into the vector pET43.1a downstream of NusA, separated by a histidine tag $(6 \times)$ and a 2 -amino acid spacer containing a thrombin cleavage site. 


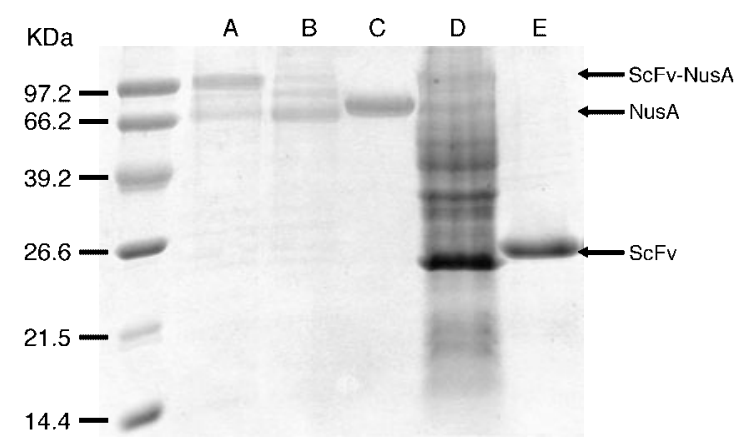

Fig. 2. Expression and purification of 14D9-ScFv NusA fusion constructs. Lane A: 14D9 ScFv-NusA fusion protein expressed in the cytoplasm of BL21(DE3) TrxB-, Gor ${ }^{-}$cells after purification with IMAC. Lane B: 14D9 ScFv-NusA fusion protein expressed in the cytoplasm of BL21(DE3) cells after purification with IMAC. Lane C: NusA protein expressed in the cytoplasm of BL21(DE3) cells after purification with IMAC. Lane D: Total cell extract for the expression of $14 \mathrm{D} 9 \mathrm{ScFv}$ without NusA in BL21(DE3) TrxB-, Gorcells. Lane E: ScFv purified from a hapten affinity column after filtration through a $\mathrm{Ni}^{2+}-\mathrm{NTA}$ column.

Plasmid pET-14D9nus was transformed into Escherichia Coli cells BL21(DE3), TrxB-,Gor-, which have an oxidizing cytoplasmic environment favorable for the expression of disulfide-bridged proteins (Details of the hapten-affinity column preparation and use will be described elsewhere). These cells grow quite slowly compared to the BL21(DE3) wild type. After induction overnight, the fusion protein was purified by $\mathrm{Ni}^{2+}$-NTA chromatography (IMAC). Two main bands were observed in the reducing SDS-PAGE (Fig. 2, lane A), one corresponding to a molecular mass of ca. $82 \mathrm{kDa}$, the other with a relatively low molecular mass appearing close to NusA (Fig. 2, lane $\mathrm{C}$, theoretical mass of $54 \mathrm{kDa}$ ). Between these two main bands, some smeared bands suggested the degradation of unfolded fusion proteins; the second main band (NusA) might be the remainder of such degradation. The expression yield was calculated from total elution from the IMAC and reached a satisfactory level of $3 \mathrm{mg} /$ litre LB medium.

Purification of the ScFv-NusA construct by haptenaffinity chromatography gave $14 \mathrm{D} 9 \mathrm{ScFv}$ and NusA in equal amounts, this due to the cleavage by proteolytic impurities during sample dialysis and concentration after elution from the column. The 14D9 $\mathrm{ScFv}$ fragment was, therefore, cleaved on purpose by treatment with thrombin, for which a cleavage site is present in the 20amino acid linker between NusA and the $\mathrm{ScFv}$, and purified by filtration through a $\mathrm{Ni}^{2+}$-NTA column followed by hapten-affinity chromatography. The product isolated showed only one band at $28 \mathrm{kDa}$, indicative of a high purity and integrity (Fig. 2, lane E). The overall yield of the expressed $\mathrm{ScFv}$ domain thus isolated from the NusAfusion protein amounted to $0.5 \mathrm{mg} / \mathrm{liter} \mathrm{LB}$ medium. For comparison, the 14D9 Fab fragment was prepared from the hybridoma-produced monoclonal antibody by papain digestion (25), and purified by hapten-affinity chromatography.

The functionality of the 14D9 ScFv-NusA fusion protein and the cleaved $14 \mathrm{D} 9-\mathrm{ScFv}$ was compared to the 14D9-Fab fragment by testing the chemical catalysis of

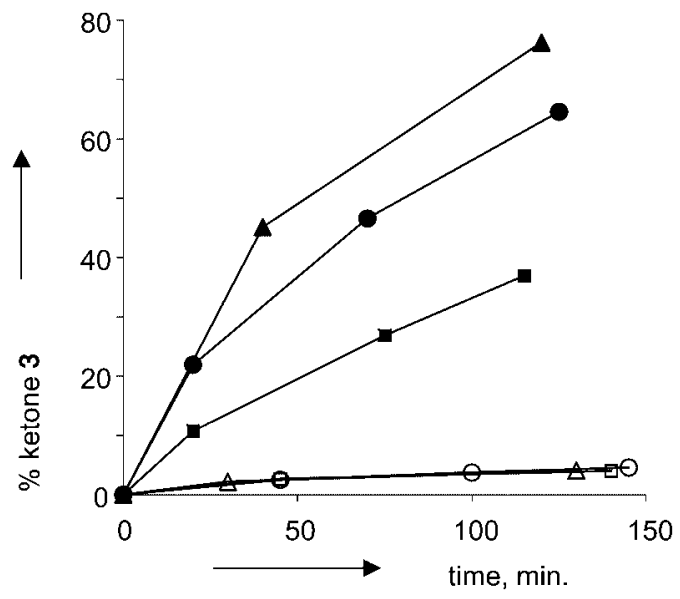

Fig. 3. Catalytic activity assay for 14D9 antibodies. Percent conversion of enol ether $\mathbf{2}$ to ketone $\mathbf{3}$ is shown as a function of time. Measured by peak integration of RP-HPLC. Conditions: $300 \mu \mathrm{M}$ substrate 2 in aq. PBS with $1.5 \% \mathrm{v} / \mathrm{v}$ acetonitrile, $1 \mathrm{mg} / \mathrm{ml}$ protein, $25^{\circ} \mathrm{C}$. (solid square): catalytic reaction of 14D9 ScFv-nusA fusion protein; (open square): inhibition of 14D9 ScFv-nusA fusion protein with $50 \mu \mathrm{M}$ hapten 1b; (solid triangle): catalytic reaction of 14D9 Fab purified from hybridoma; (open triangle): inhibition of 14D9 Fab with $50 \mu \mathrm{M}$ hapten $1 \mathrm{~b}$; (solid circle): catalytic reaction of 14D9 $\mathrm{ScFv}$ cleaved from the 14D9 ScFv-nusA fusion protein; (open circle): inhibition of 14D9 ScFv with $50 \mu \mathrm{M}$ hapten $\mathbf{1 b}$.

the enantioselective protonation of enol ether 2 to produce ketone $(S)-3$, which can be recorded by HPLC (Fig. 1). The protein samples were tested at an equal concentration of $1 \mathrm{mg} / \mathrm{ml}$ (as measured by optical density) at $\mathrm{pH}$ 7.4 in the presence or absence of the activesite-specific hapten inhibitor $\mathbf{1 b}$. All three samples catalyzed the formation of ketone 3 to a comparable level. In all three cases, the activity was quantitatively inhibited to the background level in the presence of the 14D9-specific hapten 1b. Chiral-phase column analysis of the ketone formed showed that all three samples catalyzed the formation of the $S$-enantiomer of ketone 3 exclusively, in agreement with the absolute control of enantioselectivity achieved by antibody 14D9 for this reaction (15), with the amount of racemate present in the sample corresponding to the level of the background reaction as calculated from the hapten-inhibited reaction. To examine disulfide bridge formation, the purified 14D9 $\mathrm{ScFv}-\mathrm{NusA}$ and $\mathrm{ScFv}$ were treated with $10 \mathrm{mM} \beta$-mercaptoethanol before activity measurement. There was a complete loss of catalysis in the sample, indicating the importance of disulfide bridges to functionality, and confirming that correct disulfide bond formation occurred in the cytoplasm.

To investigate the solubilizing ability of the NusA protein, pET-14D9nus was transformed into BL21(DE3) wild type, which should not support disulfide bridge formation in the cytoplasm. The purified cytoplasmic extract showed a pattern similar to the expression in oxidizing cytoplasm, but with a very low relative depth ratio of intact fusion protein to NusA (Fig. 2, lane B). In addition, the fusion protein band located at $82 \mathrm{kDa}$ disappeared after storage overnight at $4^{\circ} \mathrm{C}$, indicating degradation and structural instability due to the lack of disulfide bonds in the reducing cytoplasm. 


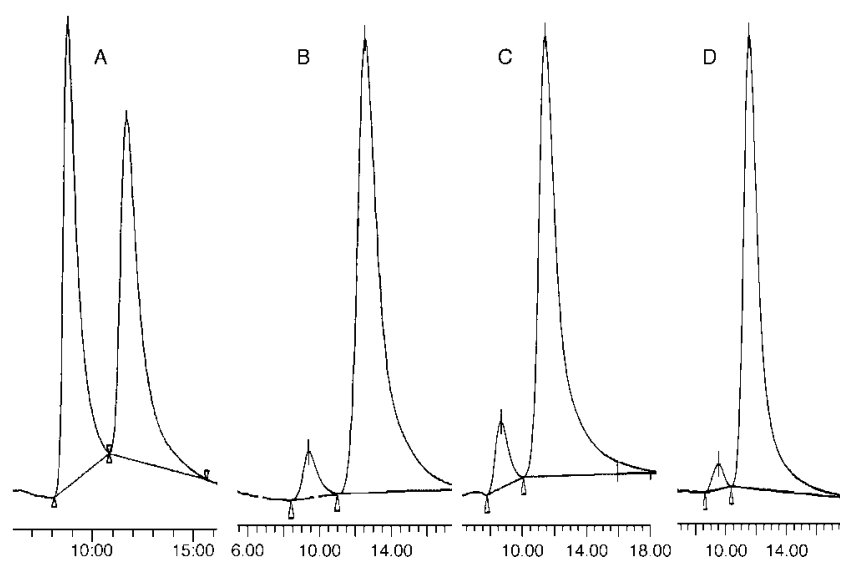

Fig. 4. Enantioselectivity assay for 14D9 antibodies. The peak of product ketone 3 from the analytical RP-C18 column was collected and lyophilized, and the residue taken was up in hexane/isopropanol $=1: 1$, and analyzed on a chiral-phase column (Chiralpak OD, Daicel, $22 \mathrm{~cm} \times 0.45 \mathrm{~cm}$ ), which allows the separation of the two enantiomeric products (eluent: hexane/isopropanol=7:3;1 ml/min) as $t_{\mathrm{R}}(R)-\mathbf{3}=8.6 \min , t_{\mathrm{R}}(S)-3=12.4$ min. (A) racemic ketone 3 produced by treatment of enol ether 2 with $0.1 \% \mathrm{TFA}, \mathrm{R} / \mathrm{S}=49 \% / 51 \%$. (B): $(S)$-ketone 3 from the reaction with $14 \mathrm{D} 9-\mathrm{Fab}, \mathrm{R} / \mathrm{S}=6 \% / 94 \%$; $(\mathrm{C})$ : $(S)$-ketone 3 from the reaction with $14 \mathrm{D} 9 \mathrm{ScFv}$-nusA fusion protein, $\mathrm{R} / \mathrm{S}=8 \% / 92 \%$; (D): $(S)$-ketone 3 from the reaction with 14D9 $\mathrm{ScFv}$ protein, $\mathrm{R} / \mathrm{S}=3 \% / 97 \%$.

Recombinant antibody expression is strongly dependent on primary sequence (26), and the success obtained with the NusA fusion construct might be entirely due to the 14D9 itself. To test this point, the direct expression of 14D9-ScFv without NusA was also investigated. Thus, the NusA $6 \mathrm{x}$ histidine tag and spacer were deleted, and the 14D9-ScFv fragment was cloned downstream of the T7 promoter to give plasmid pET-14D9. Expression of this plasmid yielded most of the $14 \mathrm{D} 9-\mathrm{ScFv}$ as an inclusion body, which was retained in the cytoplasmic pellet even at low temperature $\left(22^{\circ} \mathrm{C}\right)$ (Fig. 2, lane D). Hapten affinity chromatography gave only a tiny peak of $\mathrm{ScFv}$ that was too small to be quantitated and isolated. These experiments show that $14 \mathrm{D} 9-\mathrm{ScF} v$ alone is not expressed in a functional soluble form, thereby highlighting the key role of NusA-tag as a solubilizing agent for the antibody.

\section{DISCUSSION}

Antibody expression in recombinant format must be appreciated from the point of view of functionality, convenience, and overall yield. Here we present the overexpression of a catalytic antibody fragment 14D9, which accelerates an abiological, enantioselective protonation reaction on synthetic substrate 2 with a rate enhancement of $k_{\text {cat }} / k_{\text {uncat }}=10^{4}$. This rate enhancement is very good for an antibody, but by no means comparable to that of an enzyme, and requires fair amounts of functional protein to provide a signal in the HPLC assay used for activity detection. Considering that the activity appears in direct proportion to the amount of functional protein and that there is no possibility for signal amplification as is possible with ELISA-type activity tests, the evidence for functionality presented here can be considered as particularly strong. The evidence is reinforced by the obser- vation of the specific inhibition of activity by the small molecule hapten $\mathbf{1 b}$ in all cases, to the extent of the enantioselectivity measured by chiral phase HPLC analysis of ketone 3. It must also be mentioned that the catalysis of this enantioselective process by enzyme impurities is highly improbable as the enol ether functional group is virtually unknown in natural products, and no enzymes are known that catalyze this reaction type.

As for convenience, the cloning procedure used to construct the 14D9-ScFv NusA fusion vector from the 14D9 hybridoma cell line involved only a minimal set of standard operations. Purification of the expressed fusion protein by simple IMAC using the His-tag provided an antibody sample of sufficient purity for activity detection. Remarkably, the 14D9-ScFv fragment is not expressed in a soluble functional form when expressed alone within the oxidizing cytoplasm of $E$. coli BL21(DE3), TrxB-, Gor- $^{-}$, but appears almost exclusively as insoluble inclusion bodies. While the ScFv-NusA fusion product is formed in a stable form under these conditions, expression in the wild-type reducing cytoplasm provided only an unstable product that was quickly degraded. These results suggest that NusA proteins act as solubilizing agents, which allows the ScFv fragment to properly fold without forming insoluble aggregates. However, proper folding is tied to the formation of the structurally essential disulfide bridges. Indeed the rapid degradation of the $\mathrm{ScFv}$ portion of the fusion construct under the reducing wild-type conditions suggests that $\mathrm{ScFv}$ is not properly folded under these conditions, but yet remains in a soluble form and is, therefore, particularly vulnerable to the action of proteases. To compare in vivo folding with the in vitro refolding procedure, the $14 \mathrm{D} 9 \mathrm{ScFv}$ inclusion body was refolded by two popular ScFv refolding protocols (31, 32 ). All attempts to refold failed, implying that some factors in the cytoplasm, probably chaperones, might facilitate the folding of $\mathrm{ScFv}$ in vivo. Our experiment with antibody 14D9, whose $\mathrm{ScFv}$ fragment is not suited for cytoplasmic expression, suggests that the NusA fusion format should be easily transferable to other antibodies. This NusA fusion method might be generally useful as an alternative for functional antibody expression.

The calculated yield of $3 \mathrm{mg} /$ liter of functional fusion protein obtained lies well within the range accessible without optimization for antibody expression systems. The lower specific activity of the 14D9 ScFv-NusA fusion protein compared with the purified 14D9Fab and 14D9 $\mathrm{ScFv}$ fragments is partly explained by its higher molecular mass, but is certainly also due to the fact that the protein purified by IMAC is not pure and contains NusA from which the $\mathrm{ScFv}$ has been cleaved (Fig. 2), as evidenced by the fact that only $1.4 \mathrm{mg} / \mathrm{liter}$ of 14D9 ScFvNusA fusion protein was isolated after hapten-affinity chromatography. The key point is that no refolding operation was undertaken to isolate an active sample of 14D9 ScFv-NusA fusion protein, and that the activity of this sample establishes that the $\mathrm{ScFv}-\mathrm{NusA}$ fusion protein is indeed functional as expressed in the cytoplasm. While this is not necessarily important for expression, it becomes critical from the perspective of setting up a genetic selection system to improve the catalytic efficiency of antibodies. Indeed, selection schemes based on metabolic selection are envisioned as the best approach 
to improve the activity of catalytic antibodies over rounds of mutation and selection. Cytoplasmic expression of functional antibodies is particularly important in that respect as most genetic selection schemes should involve the catalysis of chemical reactions taking place within the cytoplasm, such as the catalysis of key metabolic reactions $(11,12)$ or the liberation of essential growth factors from synthetic precursors. Catalytic antibody 14D9 has been shown to catalyze a variety of processes, such as epoxide and acetal hydrolysis $(12,27-30)$. Some of these might be amenable to the release of an essential growth factor, for example biotin, from a specifically synthesized substrate, and future experiments will address this point.

This work has been supported by the Swiss National Science Foundation. The pComb3H-myc vector was a kind gift of Dr. Carlos Barbas, The Scripps Research Insitute, La Jolla.

\section{REFERENCES}

1. Pluckthun, A. (1991) Antibody engineering: advances from the use of Escherichia coli expression systems. Bio/Technology $\mathbf{9}$, 545-551

2. Carter, P., Kelley, R.F., Rodrigues, M.L., Snedecor, B., Covarrubias, M., Velligan, M.D., Wong, W.L., Rowland, A.M., Kotts, C.E., Carver M.E., Yang, M., Bourell, J.H., Shepard, H.M., and Herner, D. (1992) High level Escherichia coli expression and production of a bivalent humanized antibody fragment. Bio/ Technology 10, 163-167

3. Barbas, C.F. and Wagner, J. (1995) Synthetic human antibodies: selecting and solving functional proteins. Methods: $a$ Companion to Methods Enzymol. 8, 94-103

4. Skerra, A. and Plückthun, A. (1988) Assembly of a functional immunoglobulin Fv fragment in Escherichia coli. Science 240, 1038-1041

5. Arndt, K.M., Muller, K.M., and Pluckthun, A. (2001) Helix-stabilized $\mathrm{Fv}$ (hsFv) antibody fragments: substituting the constant domains of a Fab fragment for a heterodimeric coiled-coil domain. J. Mol. Biol. 31, 221-228

6. Tramontano, A., Janda, K.D., and Lerner, R.A. (1986) Catalytic antibodies. Science 234, 1566-1570

7. Pollack, S.J., Jacobs, J.W., and Schultz, P.G. (1986) Selective chemical catalysis by an antibody. Science 234, 1570-1573

8. (a) Thomas, N.R. (1996) Catalytic antibodies: reaching Adolescence? Nat. Prod. Rep. 13, 479-511 (b) Stevenson, J.D. and Thomas, N.R. (2000) Catalytic antibodies and other biominetic catalysts. Nat. Prod. Rep. 17, 535-537

9. Proba, K., Ge, L., and Plückthun, A. (1995) Functional antibody single-chain fragments from the cytoplasm of Escherichia coli: influence of thioredoxin reductase(TrxB). Gene 159, 203207

10. Smiley, J.A. and Benkovic, S.J. (1994) Selection of catalytic antibodies for a biosynthetic reaction from a combinatorial cDNA library by complementation of an auxotrophic Escherichia coli: antibodies for orotate decarboxylation. Proc. Natl Acad. Sci. USA 91, 8319-8323

11. Tang, Y., Hicks, J.B., and Hilvert, D. (1991) In vivo catalysis of a metabolically essential reaction by an antibody. Proc. Natl Acad. Sci. USA 88, 8784-8786

12. Reymond, J.L., Janda, K.D., and Lerner, R.A. (1991) Antibody catalysis of glycosidic bond hydrolysis. Angew. Chem. Int. Ed. Engl. 30, 1711-1713

13. Jahanghiri, G.K. and Reymond, J.L. (1994) Antibody-catalyzed hydrolysis of enol ethers. 2. Structure of the antibody - transition state complex and origin of the enantioselectivity. J. Amer. Chem. Soc. 116, 11264-11274
14. Shabat, D., Itzhaky, H., Reymond, J.L., and Keinan, E. (1995) Antibody catalysis of a reaction otherwise strongly disfavored in water. Nature $\mathbf{3 7 4}, 143-146$

15. Reymond, J.L., Reber, R.A., and Lerner, R.A. (1994) Enantioselective, multigram-scale synthesis with a catalytic antibody. Angew. Chem. Int. Ed. Engl. 33, 475-477

16. Wilkinson, D.L. and Harrison, R.G. (1991) Predicting the solubility of recombinant proteins in Escherichia coli. Bio/Technology $\mathbf{9}, 443-448$

17. Prinz, W.A., Aslund, F., Holmgren, A., and Beckwith, J. (1997) The role of the thioredoxin and glutaredoxin pathways in reducing protein disulfide bonds in the Escherichia coli cytoplasm. J. Biol. Chem. 272, 15661-15667

18. Takahashi, N., Kakinuma, H., Liu, L., Nishi, Y., and Fujii, I. (2001) In vitro abzyme evolution to optimize antibody recognition for catalysis. Nat. Biotechnol. 19, 563-567

19. Barbas, C.F., Kang, A.S., Lerner, R.A., and Benkovic, S.J. (1991) Assembly of combinatorial antibody libraries on phage surfaces: the gene III site. Proc. Natl Acad. Sci. USA 88, 79787982

20. Details of the hapten-affinity column preparation and use will be described elsewhere

21. Sinha, S.C. and keinan, E. (1995) Catalytic antibodies in organic synthesis. Asymmetric synthesis of (-)- $\alpha$ - multistritin. J. Amer. Chem. Soc. 117, 3653-3654

22. Huse, W.D., Sastry, L., Iverson, S.A., Kang, A.S., Alting-Mees, M., Burton, D.R., Benkovic, S.J., and Lerner, R.A. (1989) Generation of a large combinatorial library of the immunoglobulin repertoire in phage lambda. Science 246, 1275-1281

23. Filpula, F., Mcguire, J., and Whitlow, M. (1993) Production of single-chain Fv monomers and multimers in Antibody Engineering (McCafferty, J., Hoogerboom, H.R., and Chiswell, D.J., eds.) pp. 253-268, IRI Press, New York

24. Derman, A.I., Prinz, W.A., Berlin, D., and Beckwith, J. (1993) Mutations that allow disulfide bond formation in the cytoplasm of Escherichia coli. Science 262, 1744-1747

25. Porter, R.R. (1959) The hydrolysis of rabbit $\gamma$-globulin and antibodies with crystalline papain. J. Biochem. 73, 119-127

26. Plückthun, A., Krebber, A., Krebber, C., Horn, U., Knüpfer, U., Wenderoth, R., Nieba, L., Proba., K., and Riesenberg, D. (1996) Producing antibodies in Escherichia coli:from PCR to fermentation in Antibody Engineering (McCafferty, J., Hoogerboom, H.R., and Chiswell, D.J., eds.) pp. 203-252, IRI Press, New York

27. Sinha, S.C., Keinan, E., and Reymond, J.L. (1993) Antibodycatalyzed reversal of chemoselectivity. Proc. Natl Acad. Sci. USA 90, 11910-11913

28. Sinha, S.C., Keinan, E., and Reymond, J.L. (1993) Antibodycatalyzed enantioselective epoxide hydrolysis. J. Amer. Chem. Soc. 115, 4893-4894

29. Shabat, D., Sinha, S.C., Reymond, J.L., and Keinan, E. (1996) Catalytic antibodies as probes of evolution: modelling of a primordial glycosidase. Angew. Chem. Intl. Ed. Engl. 35, 26282630

30. Shabat, D., Shulman, H., Itzhaky, H., Reymond, J.L., and Keinan, E. (1998) Enantioselectivity vs. kinetic resolution in antibody catalysis: formation of the (S) product despite preferential binding of the (R) intermediate. Chem. Commun. 17591760

31. Buchner, J., Pastan, I., and Brickmann, U. (1992) A method of increasing the yield of properly folded recombinant fusion proteins: single-chain immunotoxins from renaturation of bacterial inclusion bodies. Anal. Biochem. 205, 263-270

32. Tsumoto, K., Shinoki, K., Kondo, H., Uchikawa, M., Juji, T., and Kumagai, I. (1998) Highly efficient recovery of functional single-chain $\mathrm{Fv}$ fragments from inclusion bodies overexpressed in Escherichia coli by controlled introduction of oxidizing reagent-application to a human single-chain $\mathrm{Fv}$ fragment. $J$. Immunol Methods. 219, 119-129 